\title{
Atributos da embalagem e intenção de compra de suco e néctar de laranja
}

\section{Attributes of packing and intention for purchase towards orange juice and nectar}

\author{
Marcela Tostes Frata ${ }^{1}$; Marta de Toledo Benassi; \\ Valéria Paula Rodrigues Minim³; Sandra Helena Prudencio ${ }^{2 *}$
}

\section{Resumo}

\begin{abstract}
Atributos de cinco embalagens comerciais de suco e néctar de laranja foram avaliados por meio das técnicas grupos de foco e análise conjunta. Foram levantados os atributos e níveis, marca (muito conhecida e menos conhecida), preço (alto e baixo), declarações ("natural, sem conservantes, rico em vitamina C" e sem informação) e tipo de bebida (suco e néctar), como relevantes na atitude de compra de consumidores. Elaboraram-se oito imagens de embalagens contendo diferentes combinações dos atributos levantados, obedecendo ao delineamento fatorial fracionado $\left(2^{4-1}\right)$. As imagens foram avaliadas, quanto à intenção de compra, por 101 consumidores. Houve a segmentação dos consumidores em três grupos de acordo com a similaridade no comportamento de compra. O conhecimento prévio da marca, preço baixo e as declarações "natural", "sem conservantes" e "rico em vitamina C" na face frontal da embalagem mostram-se importantes para a maior comercialização do produto.

Palavras-chave: Grupo de foco, análise conjunta, comportamento do consumidor, análise sensorial, rotulagem
\end{abstract}

\begin{abstract}
The attributes of five packages of orange juice and orange nectar were evaluated by focus group and conjoint analysis techniques. The attributes and levels were identified such as brand name (well known and less known), price (high and low), information ("natural, "no food preservative", "vitamin C-rich" and without information) and type of juice (juice and nectar), as being relevant to consumers purchase attitude. Eight packages images containing different combinations of the chosen attributes were elaborated, according to a fractional factorial design $\left(2^{4-1}\right)$. The images were evaluated, in terms of purchase intention, by 101 consumers. There was a segmentation of the consumers in three groups according to the similarity in the purchase behavior. The previous knowledge of the brand name, low price and the declarations of "natural", "no food preservatives" and "vitamin C-rich" in the frontal part of the packing reveal to be important to improve the commercialization of the product.

Key words: Focus group, conjoint analysis, consumer's behavior, sensory analysis, labelling
\end{abstract}

1 Professor da Universidade Tecnológica Federal do Paraná, Campus Dois Vizinhos; mfrata@yahoo.com.br.

2 Professor Associado do Departamento de Ciência e Tecnologia de Alimentos, Centro de Ciências Agrárias, Universidade Estadual de Londrina, sandrah@uel.br

3 Professor Adjunto do Departamento de Tecnologia de Alimentos, Universidade Federal de Viçosa.

* Autor para correspondência 


\section{Introdução}

O Brasil é o maior produtor mundial de laranja, tendo, na safra de 2007, exportado cerca de 1,39 milhões de toneladas de suco concentrado da fruta (ASSOCIAÇÃO BRASILEIRA DE EXPORTADORES DE CÍTRICOS, 2007). No mercado brasileiro é possível encontrar várias formas de apresentação e denominação para suco de laranja, sendo as mais comuns o integral, adoçado, reconstituído e néctar.

De acordo com a legislação brasileira, o suco de laranja é a bebida não fermentada enão diluída, obtida da parte comestível da laranja (Citrus sinensis), por meio de processo tecnológico adequado (BRASIL, 2000b). Ao suco pode ser adicionado açúcar, observado o percentual máximo de dez por cento em peso, recebendo então a denominação de suco adoçado (BRASIL, 2000a). O suco reconstituído é obtido pela diluição do concentrado ou desidratado até a concentração original do integral, sendo opcional o uso da expressão: "reconstituído" (BRASIL, 1997).

$\mathrm{O}$ néctar de frutas é a bebida não fermentada, obtida da diluição em água potável da parte comestível da fruta e açúcares; ou de extratos vegetais e açúcares. Admite ainda a adição de ácidos e é destinada ao consumo direto (BRASIL, 1997). O néctar, enquanto não possuir Regulamento Técnico específico, deve conter no mínimo 30\% $(\mathrm{m} / \mathrm{m})$ de polpa, ressalvadas as exceções: fruta com elevada acidez ou sabor muito forte, ou ainda, que contenha alto conteúdo de polpa, sendo que neste caso, o conteúdo de polpa não deve ser inferior a $20 \%(\mathrm{~m} / \mathrm{m})$ (BRASIL, 2003).

O comportamento de consumidores frente a um determinado alimento pode variar em razão de suas diferenças em experiência, expectativa, auto-estima, preferência, idade, sexo, personalidade, condição sócio-econômica, grupo étnico, etc. (JAEGER, 2006). As características sensoriais dos alimentos, que são fatores importantes para escolha e compra, sofrem interferência de outros atributos como preço, apelo promocional, design, informações e expectativa do consumidor gerada pela embalagem, marketing, maneira de exposição e o tempo de permanência no supermercado, entre outros.

A tecnologia pode contribuir para aumentar a venda de alimentos, por meio de embalagens construídas com modelos convenientes, práticos, apresentadas em tamanhos e formatos diversos que atendam aos anseios do consumidor, como produtos prontos para o consumo, embalagens adaptáveis à temperatura, tamanho família ou individual (NEVES; NEVES; VAL, 1999).

Diversos estudos têm sido conduzidos com a finalidade de avaliar o efeito dos atributos das embalagens de produtos alimentícios no processo de compra e aceitação pelo consumidor (CARDELO, 1995; COSTA et al., 2000; DANTAS et al., 2004; CARNEIRO et al., 2005; DELLA LUCIA et al., 2007).

O grupo de foco (focus group) é uma técnica qualitativa de discussão interativa, em que o moderador foca a atenção do grupo em um conjunto de tópicos pré-determinados, para discutir opiniões e pontos de vista. Pode ser utilizado para identificar as características relevantes de determinado produto, que interferem na escolha dos consumidores; ou ainda, discutir conceitos de novos produtos e levantar atributos importantes de embalagens (KLEEF; TRIJP; LUNING, 2005). Esse método permite aos participantes explicar os motivos e as razões para suas atitudes, percepções e preferências (DELIZA; ROSENTHAL; SILVA, 2003). Os participantes do grupo devem ter experiência com o objeto ou problema em discussão. Uma atmosfera descontraída e informal conduz comentários espontâneos. Normalmente as sessões são gravadas para reapresentação, transcrição e análise subseqüente. $\mathrm{O}$ moderador desempenha importante papel no sucesso de um grupo de foco, estabelecendo relação com os participantes para manter ativa a discussão (MALHOTRA, 2001). 
Uma das técnicas estatísticas utilizadas para quantificar o efeito dos atributos da embalagem no processo de escolha e compra de produtos é a análise conjunta (conjoint analysis) (GREEN; KRIEGER; WIND, 2001; MOSKOWITZ; SILCHER, 2006). O objetivo é descobrir quais atributos dos produtos e seusníveis influenciamnapreferênciadoconsumidor, e o valor dado a cada um deles (KLEEF; TRIJP; LUNING, 2005). A análise conjunta consiste na aplicação de regressão linear múltipla e análise de agrupamentos para estudar o estudo conjunto de duas ou mais variáveis independentes sobre a ordenação de uma variável dependente (CARNEIRO; SILVA; MINIM, 2006). A análise permite verificar e determinar a importância relativa dos atributos dos produtos e serviços no processo de escolha e compra, sendo uma ferramenta útil para definir mudanças e adaptações, sua composição e forma de apresentação; avaliar as oportunidades de mercado para produtos, como também no desenvolvimento de novos produtos para diversos tipos de consumidores (MALHOTRA, 2001; CARNEIRO et al., 2003; MOSKOWITZ; SILCHER, 2006).

O objetivo desse trabalho foi identificar e quantificar a importância de atributos da embalagem de suco reconstituído, suco adoçado e néctar de laranja, na atitude de compra de consumidores, utilizando as técnicas grupo de foco (focus group) e análise conjunta (conjoint analysis).

\section{Material e métodos}

Grupos de foco

O grupo de foco participante no estudo de embalagens comerciais de sucos de laranja, constituiu-se de 15 mulheres e 9 homens, residentes nos Estados do Paraná e de São Paulo e foram recrutados por meio de contato pessoal. Os indivíduos consumiam suco e néctar de laranja e eram nas suas famílias responsáveis pelas compras de supermercado. Foram conduzidas 5 sessões com duração média de 2 horas cada, contendo aproximadamente 5 indivíduos por sessão.

Foram avaliadas embalagens de 1 litro cartonadas da Tetra Pak de suco adoçado, reconstituído e néctar de laranja de cinco marcas comerciais (Tabela 1). O critério de escolha das embalagens foi apresentar características diferenciadas, para permitir e facilitar a discussão entre os participantes. As embalagens foram apresentadas uma por vez e de forma aleatória.

As discussões foram mediadas pelo mesmo moderador que utilizou o seguinte roteiro de questões:

1. Você observa os rótulos dos produtos que consome?

2. O que mais chama a sua atenção?

3. O que você achou da embalagem?

4. O que você considera importante nesta embalagem?

5. O que você gostaria de ver nessa embalagem?

6. Quais são as características negativas que essa embalagem apresenta?

7. As informações sobre informação nutricional e ingredientes influenciam sua decisão de compra?

8. Você sabe diferenciar néctar de suco adoçado? Qual a expressão tem melhor impacto?

9. Você pagaria mais por néctar que por suco adoçado?

10. Você gostaria de ver alguma outra informação?

As opiniões, impressões e relatos gerados nas entrevistas foram gravados em fita cassete, transcritos e analisados com base nos termos citados com ênfase. 
Tabela 1. Embalagens avaliadas no grupo de foco.

Tipo de bebida

\begin{tabular}{|c|c|c|}
\hline 1 & $\begin{array}{l}\text { Suco de laranja } \\
\text { adoçado }\end{array}$ & $\begin{array}{l}\text { Suco produzido por indústria multinacional e embalado no Brasil. } \\
\text { A embalagem contém desenho da flor de laranjeira, gotas de orvalho e várias laranjas } \\
\text { cortadas ao meio. Possui as declarações "natural", "sem conservantes", e "rico em } \\
\text { vitamina C". }\end{array}$ \\
\hline 2 & $\begin{array}{l}\text { Suco de laranja } \\
\text { adoçado }\end{array}$ & $\begin{array}{l}\text { Suco produzido por indústria latino-americana com filial no Brasil. } \\
\text { Embalagem de cor vermelha, contendo desenho de laranjas inteiras e de cortadas ao } \\
\text { meio. Possui as declarações "novo sabor", "natural", "sem conservantes", e "frutas } \\
\text { frescas". }\end{array}$ \\
\hline 3 & Néctar de laranja & $\begin{array}{l}\text { Néctar produzido por cooperativa de produtores. } \\
\text { Embalagem de cor bordô, contendo foto de laranjas inteiras e cortadas ao meio, e gotas } \\
\text { de água. Possui as declarações "natural" e "sem conservantes". }\end{array}$ \\
\hline 4 & Néctar de laranja & $\begin{array}{l}\text { Néctar produzido por indústria multinacional e embalado no Brasil. } \\
\text { Embalagem tem como fundo um campo verde e céu azul. Mostra o desenho de } \\
\text { laranjas inteiras com folhas nas hastes e de cortadas ao meio e um copo com suco } \\
\text { caindo; pedras de gelo e gotas de água. Possui as declarações "novo produto", "sem } \\
\text { conservantes", "rico em vitamina C", e "mais sabor". }\end{array}$ \\
\hline 5 & $\begin{array}{l}\text { Suco de laranja } \\
\text { reconstituído }\end{array}$ & $\begin{array}{l}\text { Suco produzido para marca de grande rede de supermercados. } \\
\text { Embalagem tem como fundo um campo verde e céu azul. Mostra o desenho de } \\
\text { laranjeira, laranjas inteiras com folhas e cortadas ao meio, e um copo recebendo o suco } \\
\text { entornado de uma laranja. Possui as declarações "pronto para beber", "o melhor para } \\
\text { você", "natural", e "sem conservantes". }\end{array}$ \\
\hline
\end{tabular}

Desenvolvimento de perfis de estímulo

A partir dos atributos, níveis levantados (Tabela

2) e as embalagens utilizadas na etapa qualitativa, novas estampas ou perfis de estímulo foram desenvolvidas.

Tabela 2. Atributos das embalagens e seus respectivos níveis.

\begin{tabular}{cc}
\hline Atributo & Níveis/descrição \\
\hline Preço & 1- Alto: R $\$ 4,50$ \\
& 2- Baixo: R $\$ 3,65$ \\
\hline Marca & 1- Conhecida: embalagem 4 \\
& 2- Menos conhecida: embalagem 5 \\
\hline Tipo de bebida & 1- Néctar de Laranja \\
& 2- Suco de Laranja \\
\hline Declarações & 1- Com declaração: natural, sem conservantes, rico em vitamina C \\
& 2- Sem declaração \\
\hline
\end{tabular}


Os níveis do atributo preço ( $\mathrm{R} \$ 3,65$ e 4,50) foram definidos de acordo com a variação média de preços para sucos e néctares de laranja em supermercados, no período do estudo. Para a marca, foram utilizadas como base a marca do produto 4, por ter sido a mais citada como conhecida, e a marca do suco 5 por se ser menos conhecida para o tipo de produto avaliado.

Com respeito ao tipo de bebida, os termos néctar de laranja e suco sem adição de açúcar foram citados com maior freqüência no estudo qualitativo. Foi relatado que a expressão "suco adoçado" presente em algumas embalagens, trazia conotação negativa ao produto, portanto esse atributo não foi escolhido para fazer parte das análises de intenção de compra.

Em relação às declarações na face frontal da embalagem, as mais citadas nos grupos de foco foram natural, sem conservantes e rico em vitamina
C. Dessa forma, optou-se por utilizar os níveis "com" e "sem" declaração.

Tendo em vista o número de fatores, optou-se por utilizar o delineamento fatorial fracionado $\left(2^{4-1}\right)$ para não sobrecarregar os participantes com número excessivo de imagens (Tabela 3), prevenindo a ocorrência de fadiga e rotina nas respostas (GREEN, KRIEGER; WIND, 2001; CARNEIRO et al., 2005). Esse delineamento é de resolução IV, onde os efeitos principais estão confundidos com os efeitos das interações entre 3 fatores (BOX; HUNTER; HUNTER, 2005).

Empregaram-se os programas Corel PhotoPaint 12 (COREL CORPORATION, 2004), MGI PhotoSuite SE (SONIC SOLUTIONS, 2006) e Microsoft PowerPoint (MICROSOFT CORPORATION, 2000) para a manipulação das figuras. Foram desenvolvidas somente as faces frontais das embalagens modificadas. $\mathrm{O}$ delineamento permitiu a combinação dos atributos e níveis gerando oito perfis de estímulo (Tabela 3).

Tabela 3. Delineamento experimental usado na análise conjunta.

\begin{tabular}{ccccc}
\hline Perfis de estímulo & Marca & Tipo de bebida & Declaração & Preço \\
\hline $\mathbf{1}$ & Muito conhecida & Suco & Com & Baixo \\
$\mathbf{2}$ & Muito conhecida & Néctarh & Com & Alto \\
$\mathbf{3}$ & Muito conhecida & Suco & Sem & Alto \\
$\mathbf{4}$ & Muito conhecida & Néctar & Sem & Baixo \\
$\mathbf{5}$ & Menos conhecida & Suco & Sem & Baixo \\
$\mathbf{6}$ & Menos conhecida & Néctar & Sem & Alto \\
$\mathbf{7}$ & Menos conhecida & Suco & Com & Alto \\
$\mathbf{8}$ & Menos conhecida & Néctar & Com & Baixo \\
\hline
\end{tabular}

Avaliação dos perfis de estímulo e medida da intenção de compra

Participaram do teste 101 consumidores potenciais do produto, dentre estudantes e funcionários da Universidade Estadual de Londrina e outros indivíduos residentes na cidade de Londrina.
A descrição do grupo de consumidores foi realizada por meio de questionários. Antes da realização das avaliações, os consumidores foram orientados para comportar-se como se estivessem diante da prateleira de um supermercado, escolhendo suco de laranja processado. 
Os perfis de estímulo foram avaliados por meio de exposição visual, utilizando o equipamento de projeção data show, em 10 sessões, com aproximadamente 10 participantes por sessão. Todas as embalagens foram apresentadas em um único slide, para que pudessem ter uma visão global do conjunto, na tentativa de se aproximar da disposição das caixas na prateleira do supermercado. Em seguida, apresentou-se para todos os participantes a primeira embalagem contendo somente a imagem de fundo da face frontal, sem nenhuma informação sobre os fatores (atributos) e níveis em estudo. A apresentação dessa embalagem teve como objetivo retirar o efeito da primeira amostra (COSTA et al., 2000) ou o impacto que o primeiro tratamento apresentado poderia causar sobre a avaliação das demais amostras.

Posteriormente as embalagens codificadas com algarismos de três dígitos foram apresentadas com o mesmo tempo de exposição de cada slide, de forma seqüencial e aleatória para cada sessão. Cada perfil de estímulo foi avaliado quanto à intenção de compra em escala estruturada mista de sete pontos, com terminologia descritiva nos pontos 7 (definitivamente compraria) e 1 (definitivamente não compraria).

Os dados foram submetidos à análise conjunta por meio do programa estatístico Sas Institute Inc (1996). Foram calculados os graus de utilidade (part-worths) dos efeitos principais e das interações dos tratamentos para cada um dos consumidores, procedendo-se uma análise individual. Os consumidores foram agrupados pelo método average linkage (distância média entre grupos) e a distância Euclidiana como medida de similaridade, tendo como regra de decisão a proximidade de um em relação ao outro. Assim, aqueles com características homogêneas quanto à intenção de compra de um produto foram enquadrados em um mesmo grupo, ou seja, os grupos foram formados por consumidores que apresentaram graus de utilidade semelhantes.
Os graus de utilidade foram estimados a partir da análise de regressão linear múltipla com variáveis mudas (dummy variables), pelo método dos mínimos quadrados (CARNEIRO et al., 2003). A análise agregada foi realizada para cada grupo de consumidores e as os graus de utilidade foram estimadas por grupo, considerando-se as médias estimadas no modelo individual.

\section{Resultados e discussão}

Grupos de foco

\section{Descrição dos participantes}

A maioria dos participantes pertencia ao sexo feminino(62\%). Houve uma distribuição homogênea na faixa etária, sendo três grupos (15 a 25; 25 a 35; 35 a 50 anos) com $29 \%$ de participantes cada; e com quarto grupo de indivíduos com idade superior a 50 anos (13\%). A maioria lia freqüentemente rótulos dos produtos (71\%), possuía curso superior completo (38\%), com renda familiar variando de 5 a 10 salários-mínimos (38\%). Os indivíduos declararam observar o preço (100\%), a marca (71\%), a data de validade (71\%), a informação nutricional (54\%) e os ingredientes (29\%) no momento da compra.

\section{Levantamento de atributos}

Foram levantados termos ou atributos das embalagens considerados importantes pelos participantes. As impressões dos participantes em relação a cada uma das cinco embalagens estão descritas a seguir.

Embalagem 1: "O desenho está bem feito, possui detalhes de frescor". "A flor de laranjeira é aspecto positivo". "A embalagem é bonita". "A cor da laranja está muito forte, parecendo cor de tangerina ou de fruta passada". "As declarações natural, sem conservantes e rico em vitamina $\mathrm{C}$ são importantes". "As informações na face lateral da embalagem são visíveis”. “A data de validade está 
visível”. "A marca é bem conceituada, porém é mais associada ao iogurte".

Embalagem 2: "A figura é pobre em detalhes e falta criatividade, mas a marca é facilmente identificada pela cor vermelha da embalagem". "A expressão suco adoçado está sem destaque, permitindo que o consumidor não perceba que o suco contém açúcar". "A embalagem faz propaganda dos outros sabores de suco". "As informações na face lateral são difíceis de ler". "As palavras frutas frescas e sem conservantes dão conotação positiva ao produto". "O prazo de validade é difícil de ser lido". "A marca é mais importante que a aparência da embalagem". "O preço costuma ser alto".

Embalagem 3: "A laranja parece estar passada, a cor da laranja deveria ser mais esverdeada ou ter contraste entre a casca e a polpa". "A laranja poderia ter folhas, o que lhe daria aspecto mais natural". "A cor bordô sobressaindo na embalagem tem conotação negativa". "As declarações natural e sem conservantes poderiam estar mais visíveis". "O prazo de validade não deve ser colocado tão próximo ao número de lote, pois dificulta a visualização". "A informação dos ingredientes poderia estar com letras maiores". "As palavras em espanhol dão conotação negativa ao produto". "Por ser produto de cooperativa, seria esperado menor preço que para os demais".

Embalagem 4: "A embalagem é moderna e colorida". "A figura contendo gotas de água dá impressão de frescor e chama a atenção de quem está com sede". "Poderia conter o pomar de laranja, já que possui o campo verde no fundo". "As letras da face lateral são muito pequenas, entretanto é interessante a informação sobre as necessidades diárias de vitaminas". "A data de validade está fácil de entender". "As declarações rico em vitamina C e sem conservantes são importantes para a escolha do produto". "A expressão mais sabor não é um fator decisivo na compra”. "A marca é conhecida e bem aceita".
Embalagem 5: "A figura é criativa". "A figura da laranjeira dá conotação de suco natural, entretanto a figura deveria ser menor, dando-se destaque à fruta". "A embalagem é muito escura, a cor azul combina com chocolate do que com suco". "O título e as informações na face frontal da embalagem estão mal destacados". "A face lateral é ilegível, com letras pequenas e o conjunto sem destaque". "Poderia estar escrito sem açúcar". "A embalagem possui receita". "A durabilidade de 24 horas após a abertura é muito curta". "A marca é menos conhecida". "Por ser marca de supermercado, dá a impressão de ser mais barato".

Os participantes relataram observar inicialmente a marca e o preço, associando as duas informações. Em relação às declarações presentes na face frontal, a maioria deu importância as alegações "natural", "sem conservantes" e "rico em vitamina C". Outras declarações presentes em algumas embalagens não foram consideradas importantes para a decisão de compra.

A maioria dos participantes observou o prazo de validade impresso nas embalagens, e mencionou, em alguns casos, que este deveria ser visível e ter destaque. Com relação às figuras, houve preferência de desenho à fotografia. A presença do copo de suco foi considerada importante, porém foi dada maior ênfase à laranja cortada ao meio, contendo folhas, com cor mais próxima da realidade. Foi citado que as figuras contendo gotículas de água dão a impressão de frescor e aguçam a vontade de beber o suco.

As opiniões foram diversas em relação ao tipo de bebida. A maioria achou que a palavra néctar possui conotação positiva. O termo suco adoçado foi considerado negativo, porém duas pessoas, que preferiam suco com açúcar, gostaram da declaração "suco adoçado", pois não haveria necessidade de fazer a adição de açúcar antes de beber. Outros participantes preferiram suco sem adição de açúcar devido ao sabor natural da fruta, doçura excessiva nos sucos que contém açúcar, menor valor calórico, e incidência de diabetes em indivíduos da família. 
Os participantes mencionaram um apelo negativo para produtos com embalagens que contenham letras escuras, sem destaque e de difícil leitura, indicando a importância de informações claras e visíveis. Alguns participantes relataram gostar da propaganda de outros produtos do fabricante na face lateral da embalagem.

A partir desses resultados, os seguintes atributos foram escolhidos como relevantes na atitude de compra: preço, marca, tipo de bebida (néctar ou suco sem adição de açúcar) e declarações (natural, sem conservantes e rico em vitamina C) (Tabelas 2 e 3).

Em pesquisa realizada com refresco em pó sabor laranja, foram levantados os atributos marca, cor (laranja, amarela), informação nutricional (polpa) e preço (CALEGUER, MINIM, BENASSI, 2007). Para outros produtos, preço e marca também têm sido citados como relevantes (OUDE OPHUIS; VAN TRIJP, 1995; CARNEIRO et al., 2005; DELLA LUCIA, 2005)

\section{Conjoint analysis}

Para a avaliação dos oito perfis de estímulo gerados a partir das informações qualitativas, analisaram-se os resultados de intenção de compra da equipe de consumidores.

Após o cálculo das utilidades individuais, optou-se pela manutenção dos dados de todos os participantes da equipe de consumidores. É comum a ocorrência de consumidores que não se ajustam ao modelo adotado e a sua exclusão. Foram relatadas as exclusões de $34,5 \%$ dos consumidores em estudo com óleo vegetal (COSTA et al., 2000) e 48\%, em trabalho com couve minimamente processada (DANTAS et al., 2005).
Della Lucia (2005), em estudo com consumidores de café orgânico torrado e moído, testou as possibilidades de exclusão ou não de participantes e concluiu que havia semelhança entre os agrupamentos de consumidores obtidos nas duas formas de análise dos dados, optando pela manutenção de todos os indivíduos.

Após a análise de agrupamentos e cálculo do grau de utilidade dos grupos, obtiveram-se três grupos, constituídos, respectivamente, por 80, $12 \mathrm{e}$ 9 consumidores, caracterizados conforme a Tabela 4. Todos os participantes eram consumidores do produto, na maioria jovens (até 35 anos). Possuíam escolaridade mínima do ensino médio, no entanto o grupo era composto por diferentes faixas etárias e renda familiar.

Os atributos, seus níveis, respectivas importâncias relativas e graus de utilidade de cada grupo de consumidores estão na Tabela 5. Os graus de utilidade representam a contribuição de cada nível de cada fator (atributo) para a preferência global. São representados por valores e sinais, sendo que os maiores valores de grau de utilidade de cada atributo indicariam os componentes que corresponderiam à embalagem de maior aceitação. O sinal negativo indica que o nível em questão possui influência negativa para a intenção de compra de determinado grupo de consumidores; e o sinal positivo indica o contrário (CARNEIRO; SILVA; MINIM, 2006).

Para o grupo 1, que compreendeu a maioria dos consumidores (79\%), três atributos mostraram importância relativa igual ou superior a $25 \%$, isto é, os participantes preferiram embalagens com declarações na face principal, preço baixo e marca mais conhecida. $O$ atributo tipo de bebida apresentou importância relativa de $4,1 \%$, indicando não se tratar de fator decisivo na compra do produto (Tabela 5). 
Tabela 4. Perfil dos consumidores divididos por grupo.

\begin{tabular}{|c|c|c|c|c|}
\hline Característica & Classes & $\begin{array}{c}\text { Grupo } 1 \\
(\mathbf{n}=\mathbf{8 0})\end{array}$ & $\begin{array}{c}\text { Grupo } 2 \\
(n=12)\end{array}$ & $\begin{array}{c}\text { Grupo } 3 \\
(n=9)\end{array}$ \\
\hline \multirow{2}{*}{ Sexo } & Feminino & 56 & 67 & 22 \\
\hline & Masculino & 44 & 36 & 78 \\
\hline \multirow{4}{*}{ Faixa etária (anos) } & $15-25$ & 64 & 42 & 44 \\
\hline & $25-35$ & 23 & 33 & 44 \\
\hline & $35-50$ & 10 & 25 & 11 \\
\hline & $>50$ & 04 & - & - \\
\hline \multirow{4}{*}{ Ocupação } & Aluno & 85 & 62 & 67 \\
\hline & Professor & 01 & 08 & - \\
\hline & Funcionário & 01 & 08 & 22 \\
\hline & Outra atividade & 13 & 23 & 11 \\
\hline \multirow{4}{*}{ Escolaridade } & Ensino fundamental & - & - & - \\
\hline & Ensino médio & 51 & 17 & 56 \\
\hline & Ensino superior & 36 & 50 & 33 \\
\hline & Pós-graduação & 13 & 33 & 11 \\
\hline \multirow{3}{*}{ Renda familiar (salários-mínimos) } & 1 a 5 & 25 & 17 & 33 \\
\hline & $>5$ a 10 & 45 & 67 & 33 \\
\hline & $>10$ a 20 & 30 & 17 & 33 \\
\hline \multirow{3}{*}{ Freqüência de Leitura de Rótulos } & Freqüentemente & 64 & 58 & 33 \\
\hline & Ocasionalmente & 35 & 42 & 67 \\
\hline & Nunca & 01 & - & - \\
\hline \multirow{3}{*}{$\begin{array}{l}\text { Características que observa no } \\
\text { momento da compra }\end{array}$} & Preço & 91 & 92 & 100 \\
\hline & Marca & 81 & 67 & 89 \\
\hline & Ingredientes & 38 & 33 & 22 \\
\hline \multirow{3}{*}{$\begin{array}{l}\text { Características que observa no } \\
\text { momento da compra }\end{array}$} & Data de validade & 81 & 58 & 67 \\
\hline & Informação nutricional & 44 & 50 & 11 \\
\hline & Outros & 04 & - & 0 \\
\hline \multirow{2}{*}{$\begin{array}{l}\text { Costuma comprar esse tipo de } \\
\text { produto? }\end{array}$} & $\operatorname{Sim}$ & 100 & 100 & 100 \\
\hline & Não & - & - & - \\
\hline
\end{tabular}

$\mathrm{n}=$ número de consumidores 
Tabela 5. Resultados da análise agregada para cada grupo de consumidores.

\begin{tabular}{|c|c|c|c|}
\hline \multicolumn{4}{|c|}{ Grau de utilidade } \\
\hline Atributos e níveis / Importância relativa & $\begin{array}{c}\text { Grupo 1 } \\
(\mathrm{n}=\mathbf{8 0})\end{array}$ & $\begin{array}{l}\text { Grupo } 2 \\
(n=12)\end{array}$ & $\begin{array}{c}\text { Grupo } 3 \\
(n=9)\end{array}$ \\
\hline \multicolumn{4}{|l|}{ Marca } \\
\hline 1- Muito conhecida & 0,35 & 0,27 & 0,64 \\
\hline 2- Menos conhecida & $-0,35$ & $-0,27$ & $-0,64$ \\
\hline Importância relativa & $25,0 \%$ & $11,6 \%$ & $23,5 \%$ \\
\hline \multicolumn{4}{|l|}{ Tipo de bebida } \\
\hline 1- Néctar & $-0,06$ & 0,17 & $-1,06$ \\
\hline 2-Suco & 0,06 & $-0,17$ & 1,06 \\
\hline Importância relativa & $4,1 \%$ & $7,1 \%$ & $38,8 \%$ \\
\hline \multicolumn{4}{|l|}{ Declaração } \\
\hline 1- Com & 0,54 & 1,75 & 0,81 \\
\hline 2-Sem & $-0,54$ & $-1,75$ & $-0,81$ \\
\hline Importância relativa & $37,8 \%$ & $75,0 \%$ & $29,6 \%$ \\
\hline \multicolumn{4}{|l|}{ Preço } \\
\hline 1- Alto $(\mathrm{R} \$ 4,50)$ & $-0,47$ & $-0,15$ & $-0,22$ \\
\hline 2- Baixo (R\$ 3,65) & 0,47 & 0,15 & 0,22 \\
\hline Importância relativa & $33,2 \%$ & $6,3 \%$ & $8,2 \%$ \\
\hline
\end{tabular}

$\mathrm{n}=$ número de consumidores

O grupo 2, que representou $12 \%$ dos consumidores, se caracterizou pela maior presença de mulheres $(67 \%)$ a maioria com curso superior completo, e declarou que observava menos a marca que os participantes dos grupos 1 e 3 (Tabela 4). Para esses consumidores, a análise conjunta confirmou que a presença das declarações na face frontal era fator decisivo na compra do produto $(75 \%)$ e os demais atributos tiveram menor influência (Tabela 5), provavelmente influenciado pela maior escolaridade dos participantes.

A intenção de compra do grupo $3(9 \%$ dos consumidores) foi dirigida principalmente pelos atributos tipo de bebida $(38,8 \%)$, presença de declarações $(29,6 \%)$ e marca $(23,5 \%)$. Eles optariam por adquirir sucos em embalagens com declarações e marca muito conhecida. $\mathrm{O}$ atributo preço baixo apresentou importância relativa menor $(8,2 \%)$, porém influenciou positivamente na escolha (Tabela 5). Esse grupo era composto em sua maioria por jovens do sexo masculino (78\%), que liam com menos freqüência o rótulo e as informações nutricionais dos produtos (Tabela 4). Apesar de $100 \%$ terem relatado que observavam o preço no momento da compra (Tabela 4), esse atributo não foi o de maior importância durante a avaliação da embalagem (Tabela 5).

Considerando que nos 3 grupos a importância relativa para as declarações na face frontal da embalagem e para a marca conhecida foi positiva e maior que $10 \%$, pode-se considerar que todos os consumidores foram influenciados por esses atributos.

Existe grande evidência que a marca influencia na percepção, atitude e comportamento do consumidor. A influência da marca mais conhecida se dá pela confiança conquistada em relação aos demais produtos (JAEGER, 2006). Em estudo realizado com embalagens de café orgânico torrado e moído, Della Lucia et al. (2007) relatam que a marca conhecida afetou positivamente a intenção de compra de 93\% dos consumidores. Esses 
consumidores provavelmente relacionaram a marca conhecida à melhor qualidade do produto quando comparado com a marca menos conhecida.

Com relação ao preço, no geral a literatura relata impacto positivo. Della Lucia et al. (2007) descreveram, em estudo com consumidores de café orgânico torrado e moído, que o preço influenciou a intenção de compra de todos os consumidores, com importância relativa variando de 30,1\% a 77,1\%.

Nesse estudo, somente o grupo 1 mostrou ter a intenção de compra influenciada pelo preço. Tal comportamento pode parecer incomum, no entanto, pode haver associação do preço alto à melhor qualidade do produto, ou ainda, os outros atributos ocuparam maior posição de importância que o preço (CARNEIRO et al., 2005; ENNEKING; NEUMANN; HENNEBERG, 2007).

Para Vickers (1993), alegações de benefícios para a saúde e gosto foram fatores mais importantes que preço e marca para consumidores de iogurte de morango. Em estudo realizado com óleo de girassol, Deliza et al. (2000) identificaram três grupos de consumidores: o primeiro teve intenção de compra influenciada pela ilustração do rótulo; o segundo, pelo preço e a marca; e o terceiro, pela informação sobre como o produto foi obtido.

Com relação ao tipo de bebida, néctar ou suco, de forma geral não foi influenciou a intenção de compra do produto, sendo importante apenas para o grupo 3 ( $9 \%$ dos consumidores), que preferiu bebida do tipo suco (Tabela 5).

\section{Conclusões}

Associando-se as informações qualitativas dos grupos de foco e os resultados da análise conjunta, alguns parâmetros se destacaram como importantes na intenção de compra das bebidas de laranja. Constatou-se que a embalagem deve possuir figura que aguce a vontade de beber o suco e dê a impressão de frescor como a de uma laranja cortada ao meio, contendo folhas e com cor mais próxima da realidade. Embalagens com impressão de letras escuras, sem destaque e de difícil leitura, agregam conotação negativa ao produto.

O fato do produto ser néctar ou suco não teve grande influência na decisão de compra do consumidor. Independentemente da importância relativa atribuída aos atributos estudados ser diferenciada para cada grupo, o conhecimento prévio da marca, preço baixo e as declarações "natural", "sem conservantes" e "rico em vitamina C" na face frontal da embalagem foram considerados importantes para a intenção de compra.

\section{Referências}

ASSOCIAÇÃO BRASILEIRA DOS EXPORTADORES DE CÍTRICOS - ABECITRUS. Exportações de FCOJ - Safra Atual. Ribeirão Preto, 2007. Disponível em: $<$ http://www.abecitrus.com.br/exporta_br.html $>$. Acesso em: 20 maio 2008.

BOX, G. E. P.; HUNTER, J. S.; HUNTER, W. G. Statistics for experiments: designs, innovation and discovery. New Jersey: John Wiley \& Sons, Inc., 2005. p. 235-280.

BRASIL. Ministério da Agricultura, Pecuária e Abastecimento. Decreto n ${ }^{\circ}$ 2.314, de 4 setembro 1997, Regulamenta a Lei $\mathrm{n}^{\circ} 8.918$, de 14 de julho de 1994. Diário Oficial da União, Brasília, DF, 4 set. 1997, Seção 1, p. 19549.

BRASIL. Ministério da Agricultura, Pecuária e Abastecimento. Decreto n ${ }^{\circ} 3510$, de 16 junho 2000. Altera dispositivos do Regulamento aprovado pelo Decreto $\mathrm{n}^{\circ}$ 2.314, de 4 de setembro de 1997, que dispõe sobre a padronização, a classificação, o registro, a inspeção, a produção e a fiscalização de bebidas. Diário Oficial da União, Brasília, DF, 16 jun. 2000a, Seção 1.

BRASIL. Ministério da Agricultura, Pecuária e Abastecimento. Instrução Normativa $\mathrm{n}^{\circ} 1$, de 7 janeiro 2000. Complementa padrões de identidade e qualidade para suco de laranja. Diário Oficial da União, Brasília, DF, 10 jan. 2000b, Seção 1, p. 54.

BRASIL. Ministério da Agricultura, Pecuária e Abastecimento. Instrução Normativa $n^{\circ} 12$, de 4 setembro 2003. Aprova o Regulamento Técnico para Fixação dos Padrões de Identidade e Qualidade Gerais para Suco Tropical; os Padrões de Identidade e Qualidade dos Sucos Tropicais de Abacaxi, Acerola, Cajá, Caju, Goiaba, Graviola, Mamão, Manga, Mangaba, Maracujá e Pitanga; e os Padrões de Identidade e Qualidade dos Néctares de 
Abacaxi, Acerola, Cajá, Caju, Goiaba, Graviola, Mamão, Manga, Maracujá, Pêssego e Pitanga. Diário Oficial da União, Brasília, DF, 09 set. 2003, Seção 1, p. 2.

CALEGUER, V. F.; MINIM, V. P. R.; BENASSI, M. T. Impacto da embalagem do preparado sólido para refresco sabor laranja na intenção de compra do consumidor. Brazilian Journal of Food Technology, Campinas, v. 10, n. 3, p. 159-168, 2007.

CARDELO, A. V. Sensory evaluation and food packing. Cereal Foods World, Minneapolis, v. 40, n. 7, p. 502-504, 1995.

CARNEIRO, J. D. S.; MINIM, V. P. R.; DELIZA, R.; SILVA, C. H. O.; CARNEIRO, J. C. S.; LEÃO, F. P. Labeling effects on consumer intention to purchase for soybean oil. Food Quality and Preference, Barking, v. 16 , n. 3, p. 275-282, 2005.

CARNEIRO, J. D. S.; SILVA, C. H. O.; MINIM, V. P. R. Análise conjunta de fatores. In: MINIM, V. P. R. Análise Sensorial: estudo com consumidores. Viçosa: UFV, 2006. p. 127-172.

CARNEIRO, J. D. S.; SILVA, C. H. O.; MINIM, V. P. R.; REGAZZI, A. J.; DELIZA, R.; SUDA, I. R. Princípios básicos da conjoint analysis em estudos do consumidor. Boletim da Sociedade Brasileira de Ciência e Tecnologia de Alimentos, Campinas, v. 37, n. Supl., p. 107-114, 2003.

COREL CORPORATION. Corel Photo-Paint 12. Otawa: Anniversary, 2004.

COSTA, M. C.; DELIZA, R.; ROSENTHAL, A.; HEDDERLEY, D.; FREWER, L. Non conventional technologies and impact on consumer behavior. Trends in Food Science and Technology, Cambridge, v. 11, n. 4/5, p. 188-193, 2000.

DANTAS, M. I. S.; DELIZA, R.; MINIM, V. P. R.; HEDDERLEY, D. Avaliação da intenção de compra de couve minimamente processada. Ciência e Tecnologia de Alimentos, Campinas, v. 25, n. 4, p. 762-767, 2005.

DANTAS, M. I. S; MINIM, V. P. R.; DELIZA, R.; PUSCHMANN, R. The effect of packaging on the perception of minimally processed products. Journal of International Food \& Agribusiness Marketing, New York, v. 16, n. 2, p. 71-83, 2004.

DELIZA, R.; MACFIE, H.; HEDDERLEY, D.; FREWER, L. Non conventional technologies and impact on consumer behavior. Trends in Food Science and Technology, Cambridge, v. 11, n. 4, p. 188-193, 2000.

DELIZA, R.; ROSENTHAL, A.; SILVA, A. L. S. Consumer attitude towards information on non conventional technology. Trends in Food Science and Technology, Cambridge, v. 14, n. 1/2, p. 43-49, 2003.
DELLA LUCIA, S. M. Conjoint Analysis no Estudo de Mercado de Café Orgânico. 2005. Dissertação (Mestre em Ciência e Tecnologia de Alimentos) - Universidade Federal de Viçosa, Viçosa, 2005.

DELLA LUCIA, S. M.; MINIM, V. P. R.; MINIM, L. A.; SILVA, C. H. O. Fatores da embalagem de café orgânico torrado e moído na intenção de compra do consumidor. Ciência e Tecnologia de Alimentos, , v. 27, n. 3, p. 485491, 2007.

ENNEKING, U.; NEUMANN, C.; HENNEBERG, S. How important intrinsic and extrinsic product attributes affect purchase decision. Food Quality and Preference, Barking, v. 18, n. 1, p. 133-138, 2007.

GREEN, P. E.; KRIEGER, A. M.; WIND, Y. Thirty years of conjoint analysis: reactions and prospects. Interfaces, Ohio, v. 31, n. 3, p. 56-73, 2001.

JAEGER, S. R. Non-sensory factors in sensory science research. Food Quality and Preference, Barking, v. 17, n. 1/2, p. 132-144, 2006.

KLEEF, E. V.; TRIJP, H. C. M. V.; LUNING, P. Consumer research in the early stages of new product development: a critical review of methods and techniques. Food Quality and Preference, Barking, v. 16, n. 3, p. 181-201, 2005.

MAlhotrA, N. K. Pesquisa de Marketing - uma orientação aplicada. 3. ed. Porto Alegre: Bookman, 2001.

MICROSOFT CORPORATION. Microsoft PowerPoint. San Francisco: Microsoft, 2000.

MOSKOWITZ, H. R.; SILCHER, M. The applications of conjoint analysis and their possible uses in Sensometrics. Food Quality and Preference, Barking, v. 17, n. 3/4, p. 145-165, 2006.

NEVES, M. F.; NEVES, E. M.; VAL, A. M. Doces Perspectivas do Consumo de Suco de Laranja no mundo. Gazeta Mercantil, São Paulo, 22 de nov. 1999. Caderno Interior Paulista, Opinião Econômica, p. 2.

OUDE OPHUIS, P. A. M.; VAN TRIJP, H. C. M. Perceived quality: a market driven and consumer oriented approach. Food Quality and Preference, Barking, v. 6, n. 3, p. 177-183, 1995.

SAS INSTITUTE INC. SAS Users' Guide: statistics, version 6.12. Cary: SAS Institute, 1996.

SONIC SOLUTIONS. MGI PhotoSuite SE. California: Sonic Solutions, 2006.

VICKERS, Z. M. Incorporating tasting into a conjoint analysis of taste, health claim, price and brand for purchasing strawberry yoghurt. Journal of Sensory Studies, Westport, v. 8, n. 4, p. 341-352, 1993. 